Pacific Journal of Mathematics

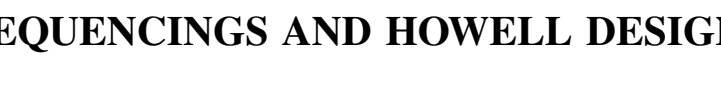




\section{SEQUENCINGS AND HOWELL DESIGNS}

\section{B. A. ANDERson AND P. A. LeOnard}

We show that if $p$ is a prime, $p \geq 5$, the cyclic group $Z_{2 p}$ has a strong symmetric sequencing. It follows that if $p$ is any prime, there is a Howell design of type $H^{*}(2 p, 2 p+2)$.

1. Introduction. Suppose $X$ is a set such that $|X|=2 n$. A Howell design on $X$ of type $H(s, 2 n)$ consists of a square array of side $s$ such that (1) each cell is either empty or contains an unordered pair of elements taken from $X$, (2) each element of $X$ appears exactly once in each row and each column of the array and (3) every unordered pair appears at most once in a cell of the array. It is easy to see that existence requires $n \leqq s \leqq 2 n-1$. If $Y \subset X$ such that $|Y|=2 n-s$ and no pair of elements of $Y$ occupy a cell of the design of type $H(s, 2 n)$, we will denote this fact notationally by writing $H^{*}(s, 2 n)$.

For information concerning the existence of Howell designs, see $[2,3,4,5,6,9]$. Howell designs of type $H^{*}(2 n-1,2 n)$ are often called Room Squares. Room Squares are now known to exist for all $n$ except $n=2,3$ [10]. In this paper we deal with the existence question for designs of type $H^{*}(2 n-2,2 n)$, or equivalently, of type $H^{*}(2 m, 2 m+2)$.

It is not difficult [9] to show that there is no design of type $H^{*}(2,4)$. However, it now seems certain that this is the only case in which a design of type $H^{*}(2 m, 2 m+2)$ fails to exist. Indeed, in [4] the existence question for these types of designs is reduced to the following.

(A) Are there designs of type $H^{*}(2 p, 2 p+2), p$ prime?

(B) Are there designs of type $H^{*}(6 p, 6 p+2), p$ prime?

(C) Are there designs of type $H^{*}(24,26), H^{*}(48,50)$ and $H^{*}(54,56)$ ?

In this paper, we give an affirmative answer to (A).

Our argument for settling (A) depends upon the following ideas. Suppose $G$ is a finite group of order $n$ with identity $e$. A sequencing of $G$ is an ordering $e, a_{2}, \cdots, a_{n}$ of all the elements of $G$ such that the partial products $e, e a_{2}, e a_{2} a_{3}, \cdots, e a_{2} \cdots a_{n}$ are distinct and hence comprise all of $G$. Gordon [8] characterized sequenceable Abelian groups as those Abelian groups with a unique element of order 2.

Definition 1. Suppose $G$ is a group of order $2 n$ with identity $e$ and unique element $g^{*}$ of order 2. A sequencing $e, a_{2}, \cdots, a_{2 n}$ 
will be called a symmetric sequencing iff $a_{n+1}=g^{*}$ and for $1 \leqq i \leqq$ $n-1, a_{n+1+i}=\left(a_{n+1-i}\right)^{-1}$.

If $g^{*}$ is the unique element of order 2 in $G$, then $g^{*}$ is in the center of $G$. Thus, symmetric sequencings

$$
S: e, a_{2}, \cdots, a_{n}, g^{*}, a_{n}^{-1}, \cdots, a_{3}^{-1}, a_{2}^{-1}
$$

have the associated partial product sequence

$$
P: e, b_{2}, \cdots, b_{n}, b_{n} g^{*}, b_{n-1} g^{*}, \cdots, b_{2} g^{*}, g^{*} .
$$

There is a natural way [1] to use $P$ to partition $G$ into 2-element sets. The element that is paired with $e$ in this partition is denoted $m ; m$ is $b_{n}$ if $n$ is even and $b_{n+1}$ otherwise. Since we will consider the cyclic groups $Z_{2 p}, p \geqq 3, p$ prime, $m$ will always denote $b_{p+1}$ in this paper. The remaining partition elements coming from $P$ form what is called a (left) even starter and $m$ is the nonidentity element of $G$ "missing" from the pairs of the starter.

Definition 2. Suppose $G$ is an Abelian group of order $2 n$ and $S$ is a symmetric sequencing of $G . \quad S$ is strong iff in the associated partial product sequence $P$

(i) $1 \leqq i<j \leqq n-1$ implies $b_{i} b_{i+1} \neq b_{j} b_{j+1}$ and

(ii) $1 \leqq i \leqq n-1$ implies $b_{i} b_{i+1} \notin\left\{e, m^{2}\right\}$.

The sequencings of Gordon are symmetric but not strong [1]. It is known [1] that a strong symmetric sequencing on an Abelian group of order $2 n$ will induce a Howell Design of type $H^{*}(2 n, 2 n+2)$. Thus, since $[3,9]$ give designs of type $H^{*}(4,6)$ and $H^{*}(6,8)$, in order to show that designs of all types $H^{*}(2 p, 2 p+2)$ exist $(p$ prime), it will suffice to show that when $p \geqq 5, p$ prime, $Z_{2 p}$ has a strong symmetric sequencing. This will be done in the next section. We note in passing that apparently the only other known family of strong symmetric sequencings occurs on the cyclic groups $Z_{p-1}$, when $p>3$ is prime and $p=5$ or $p \equiv \pm 3, \pm 13(\bmod 40)$ [3].

2. The construction. Suppose $p \geqq 3$ is a prime, $Z_{2 p}$ is the additive cyclic group of order $2 p$ and $x=2 y \in Z_{2 p}$. Note that since $x$ is even, the subgroup $\langle x\rangle$ generated by $x$ has $p$ elements. Our candidate for a strong symmetric sequencing of $Z_{2 p}$ is defined as follows.

$$
S: a_{i}=\left\{\begin{array}{l}
(i-1) x(\bmod 2 p) ; 1 \leqq i \leqq(p+1) / 2, \\
2(i-1)-p ;(p+3) / 2 \leqq i \leqq(3 p+1) / 2, \\
(i-1) x(\bmod 2 p) ;(3 p+3) / 2 \leqq i \leqq 2 p
\end{array}\right.
$$

With this definition it is easy to compute the corresponding partial 
sum sequence (note again that things are written additively in this section). The notation $\beta_{x}$ will be used for $b_{(p+1) / 2}=\left[\left(p^{2}-1\right) / 8\right] x$ and, as mentioned previously, since $p$ is odd, $m_{x}=b_{p+1}$.

$$
P: b_{i}=\left\{\begin{array}{l}
{\left[\frac{i(i-1)}{2}\right] x(\bmod 2 p) ; \quad 1 \leqq i \leqq(p+1) / 2,} \\
\left(\beta_{x}+[i-(p+1) / 2]^{2}\right)(\bmod 2 p) ;(p+3) / 2 \leqq i \leqq(3 p+1) / 2, \\
\left(\left[\frac{i(i-1)}{2}\right] x+p\right)(\bmod 2 p) ;(3 p+3) / 2 \leqq i \leqq 2 p
\end{array}\right.
$$

Although $S$ is not always a strong symmetric sequencing, it is not difficult to show that $S$ and $P$ do always have many of the properties required. Before delineating these properties, we give two examples to facilitate understanding. In each case $S$ is the sequence of $a_{i}$ 's and $P$ is the sequence of $b_{i}$ 's. The elements $\beta_{x}$ and $m_{x}$ are starred in each case, $C$ contains the set mentioned in Definition 2(i) and the underlining will be explained shortly.

EXAMPLE 1. $p=11, x=6$, arithmetic $\bmod 22$.

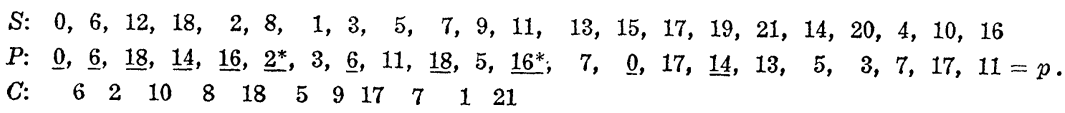

EXAMPLE 2. $p=13, x=4$, arithmetic $\bmod 26$.

$S: \quad 0,4, \quad 8,12,16,20,24,1,3, \quad 5,7,9,11,13,15,17,19,21,23,25,2,6,10,14,18,22$ $P: \underline{0}, \underline{4}, \underline{12}, \underline{24}, \underline{14}, \underline{8}, \underline{6}, 7, \underline{10}, 15, \underline{22}, 5, \underline{16}, 3^{*}, \underline{18}, 9, \underline{2}, 23, \underline{20}, 19,21,1,11,25,17,13=p$. $\begin{array}{lllllllllllllll}C: & 4 & 16 & 10 & 12 & 22 & 14 & 13 & 17 & 25 & 11 & 1 & 21 & 19\end{array}$

THEOREM 1. Suppose $p \geqq 3$ is a prime, $x=2 y \in Z_{2 p}$ and $S$ and $P$ are as defined above. Then

(i) $\left\{a_{i}: 1 \leqq i \leqq 2 p\right\}=Z_{2 p}$ (we will write this as $S=Z_{2 p}$ );

(ii) $a_{1}=b_{1}=0, a_{p+1}=b_{2 p}=p$;

(iii) $1 \leqq k \leqq p-1$ implies $a_{p+1+k}=-\left(a_{p+1-k}\right)$;

(iv) $1 \leqq j \leqq 2 p$ implies $b_{j}+p=b_{2 p-(j-1)}$;

(v) $2 \leqq i<j \leqq p+1$ implies $b_{i-1}+b_{i} \not \equiv b_{j-1}+b_{j}(\bmod 2 p)$;

(vi) $2 \leqq i \leqq p+1$ implies $b_{i-1}+b_{i} \not \equiv 0(\bmod 2 p)$.

Proof. The verification of statements (i) through (iv) is straightforward. Note that (v) and (vi) are slightly stronger statements than appear in Definition 2, although one part of that definition is not covered by these statements. We proceed with the proof of (v). For $2 \leqq i \leqq p$, let 


$$
\begin{aligned}
c_{i} & =b_{i-1}+b_{i} \\
& =\left\{\begin{array}{l}
(i-1)^{2} x(\bmod 2 p) ; 2 \leqq i \leqq(p+1) / 2, \\
2 \beta_{x}+\left[(i-(p+3) / 2)^{2}+(i-(p+1) / 2)^{2}\right] ;(p+3) / 2 \leqq i \leqq p+1 .
\end{array}\right.
\end{aligned}
$$

It is easy to see that if $2 \leqq i \leqq(p+1) / 2$, then $c_{i}$ is even while the remaining $c_{i}$ 's are odd. Thus it will suffice to show that there is no duplication in either half above.

Suppose $2 \leqq i<j \leqq(p+1) / 2$. Then

$$
\begin{aligned}
& \quad(i-1)^{2} x \equiv(j-1)^{2} x(\bmod 2 p) \\
& \text { iff }\left[(i-1)^{2}-(j-1)^{2}\right] y \equiv 0(\bmod p) \\
& \text { iff either } i \equiv j(\bmod p) \text { or } i+j \equiv 2(\bmod p) .
\end{aligned}
$$

Since neither of these conditions is possible, the even $c_{i}$ 's are distinct.

Similarly, the other half reduces to showing that if $0 \leqq i<j \leqq$ $(p-1) / 2$, then

$$
i^{2}+(i+1)^{2} \not \equiv\left[j^{2}+(j+1)^{2}\right](\bmod 2 p) .
$$

If we assume the contrary, then there are $i$ and $j$ within the specified limits such that

$$
\begin{aligned}
& i^{2}+(i+1)^{2} \equiv\left[j^{2}+(j+1)^{2}\right](\bmod 2 p) \\
& \text { iff } i(i+1) \equiv j(j+1)(\bmod p) .
\end{aligned}
$$

Let $j=i+k$ and the above reduces to

$$
\text { either } k \equiv 0(\bmod p) \text { or } 2 i+k+1 \equiv 0(\bmod p) \text {. }
$$

But since $k \leqq(p-1) / 2-i$ it follows that $2 i+k+1 \leqq p-1$ and (v) is verified.

Finally, in order to show (vi), it suffices to show that $2 \leqq i \leqq$ $(p+1) / 2$ implies $c_{i} \not \equiv 0(\bmod 2 p)$ since the other $c_{i}$ 's in the given range are odd numbers. But if $2 \leqq i \leqq(p+1) / 2$,

$$
c_{i} \equiv(i-1)^{2} x(\bmod 2 p) \text {. }
$$

Thus

$$
\begin{aligned}
& \quad c_{i} \equiv 0(\bmod 2 p) \\
& \text { iff }(i-1)^{2} y \equiv 0(\bmod p) \\
& \text { iff }(i-1)^{2} \equiv 0(\bmod p),
\end{aligned}
$$

and this is clearly false.

Note that in the two given examples, the rows labelled $C$ show the $c_{i}$ 's in each case.

Now, it is clear from Theorem 1 that if $S$ is a sequencing, it 
is symmetric and that it has several of the properties of strong symmetric sequencings. Thus, we would like to answer two questions. First, when is it the case that $S$ is a sequencing? Clearly $S$ will be a sequencing precisely when $\left\{b_{i}: 1 \leqq i \leqq 2 p\right\}=Z_{2 p}$; that is, when $P=Z_{2 p}$. The next result will show exactly when this happens. Second, when is it true that $2 m \not \equiv c_{i}(\bmod 2 \mathrm{p}), 2 \leqq i \leqq p+$ 1 ? We are also able to settle this point. Certainly if we can choose $x$ so that $P=Z_{2 p}$ and $2 m$ misses all the $c_{i}$ 's, we will have a strong symmetric sequencing.

Let $N=\{1,2, \cdots, 2 p\}$, let $Q=\{\{j, 2 p-(j-1)\}: 1 \leqq j \leqq p\}$ and suppose $V$ is a set with exactly $p$ elements such that every member of $Q$ has exactly one element in $V$. If $x=2 y \in Z_{2 p}$ is given such that $\left\{b_{r}: r \in V\right\}=\langle x\rangle$, then by Theorem 1 (iv) $\left\{b_{t}: t \in N \backslash V\right\}=\langle x\rangle+$ $p$, and in such a case, $P=Z_{2 p}$.

Definition 3. Suppose $D=\{1,2, \cdots,(p+1) / 2\}$ and $E=\{(p+$ 1)/2+2k: $1 \leqq k \leqq(p-1) / 2\}$. Then let $V=D \cup E$.

It is easy to see that $V$ contains exactly one element of each member of $Q$. In Examples 1 and 2, the underlined elements in $P$ are $\left\{b_{r}: r \in V\right\}$.

Definition 4. Suppose $x=2 y \in Z_{2 p}$ and $S$ and $P$ are constructed as usual. Then

$$
\sum_{x}=\{(0+1+\cdots+i) x(\bmod 2 p): 0 \leqq i \leqq(p-1) / 2\}
$$

and

$$
W_{x}=\left\{\left[\beta_{x}+(2 k)^{2}\right](\bmod 2 p): 1 \leqq k \leqq(p-1) / 2\right\} .
$$

Note that $\Sigma_{x} \cup W_{x}=\left\{b_{r}: r \in V\right\}$ and $\sum_{x} \cup W_{x} \subset\langle x\rangle$.

THeorem 2. If $x=2 y \in Z_{2 p}$, then $\left|\sum_{x}\right|=(p+1) / 2$ and $\left|W_{x}\right|=$ $(p-1) / 2$.

Proof. An argument very much like that used in the second half of Theorem $1(\mathrm{v})$ shows that $\left|\sum_{x}\right|=(p+1) / 2$ and it is straightforward to see that $\left|W_{x}\right|=(p-1) / 2$.

Thus, $P=Z_{2 p}$ exactly when $\sum_{x} \cap W_{x}=\phi$. In the following result we use the Legendre symbol $(a \mid p)$.

THEOREM 3. Suppose $p \geqq 3$ is a prime, $x=2 y \in Z_{2 p}$ and $S$ and $P$ are defined as usual. Then

(1) $(y \mid p)=-1$ iff $\sum_{x} \cup W_{x}=\langle x\rangle$ iff $S$ is a symmetric sequencing, 


$$
(y \mid p)=1 \text { iff } \sum_{x} \mid\left\{\beta_{x}\right\}=W_{x} .
$$

Proof. Notice first that $\sum_{x} \cap W_{x} \neq \phi$ is equivalent to saying that there exist $i, 0 \leqq i \leqq(p-1) / 2$ and $k, 1 \leqq k \leqq(p-1) / 2$ such that

$$
\left[\left(p^{2}-1\right) / 8\right] 2 y+4 k^{2} \equiv[i(i+1) / 2] 2 y(\bmod 2 p) .
$$

This is equivalent to

$$
\text { (*) } 16 k^{2} \equiv(2 i+1)^{2} y(\bmod p) .
$$

In this form it is clear that since $16 k^{2} \not \equiv 0(\bmod p)$ for any $k$ in the allowed range, $i \neq(p-1) / 2$.

It is now very easy to prove (1). If $(y \mid p)=-1$ then $\left({ }^{*}\right)$ fails to hold so that $\sum_{x} \cap W_{x}=\phi$ and hence $\sum_{x} \cup W_{x}=\langle x\rangle$. Conversely, if $\sum_{x} \cup W_{x}=\langle x\rangle$, then the cardinalities force $\sum_{x} \cap W_{x}=\phi$. If $(y \mid p)=1$, then any permissible choice of $i$ would allow the solution of $\left(^{*}\right)$ for a permissible $k$. Thus $(y \mid p)=-1$. It is apparent that $\sum_{x} \cup W_{x}=\langle x\rangle$ is equivalent to $S$ being a symmetric sequencing.

Now suppose $(y \mid p)=1$. As above, given a permissible $i$, there is a unique permissible $k$ such that $\left({ }^{*}\right)$ holds. Since different values of $i$ lead to different values of $k$, one solution to $\left(^{*}\right)$ implies ( $p-$ 1)/2 solutions. Since $i=(p-1) / 2$ has been eliminated from consideration, it follows that $\sum_{x} \mid\left\{\beta_{x}\right\}=W_{x}$. Conversely, if $W_{x}=$ $\sum_{x} \mid\left\{\beta_{x}\right\}$, then $\sum_{x} \cap W_{x} \neq \phi$ so that by $\left(^{*}\right)$ and the properties of the Legendre symbol, $(y \mid p)=1$.

It is clear from Theorem 3 that if $p \geqq 3$ is a prime, we can choose $x=2 y$ such that $S$ is a symmetric sequencing. In fact, it is not much harder to insure that $S$ is a strong symmetric sequencing. In what follows, let

$$
C=\left\{b_{i-1}+b_{i}: 2 \leqq i \leqq p+1\right\}=\left\{c_{i}: 2 \leqq i \leqq p+1\right\} .
$$

Theorem 4. Suppose $p \geqq 3$ is a prime, $x=2 y \in Z_{2 p}$ and $S$ and $P$ are constructed as usual. The following statements holds.

(1) If $p \equiv 1(\bmod 4)$, then $2 m \notin C$ iff $(y \mid p) \neq(y-1 \mid p)$.

(2) If $p \equiv 3(\bmod 4)$, then $2 m \notin C$ iff $(y \mid p)=(y-1 \mid p)$.

Proof. Certainly $2 m$ is even so that we need only concern ourselves with $\left\{c_{i}: 2 \leqq i \leqq(p+1) / 2\right\}$. Thus $2 m \in C$ iff there is an $i, 2 \leqq i \leqq(p+1) / 2$ such that

$$
(i-1)^{2} x \equiv\left(\left[\left(p^{2}-1\right) / 4\right] x+\left[(p+1)^{2}\right] / 2\right)(\bmod 2 p) .
$$

This is equivalent to each of the congruences 


$$
(i-1)^{2} y \equiv\left(\left[\left(p^{2}-1\right) / 4\right] y+\left[(p+1)^{2}\right] / 4\right)(\bmod p)
$$

and

$$
4(i-1)^{2} y \equiv(-1)(y-1)(\bmod p) .
$$

Since the limits on $i$ allow $(i-1)^{2}$ and hence $4(i-1)^{2}$ to be any quadratic residue, $2 m \in C$ iff $(y \mid p)=(-1 \mid p)(y-1 \mid p)$ and the result follows immediately.

THEOREM 5. Suppose $p \geqq 3$ is a prime, $x=2 y \in Z_{2 p}$ and $S$ and $P$ are constructed as usual. The following statements hold.

(1) If $p \equiv 1(\bmod 4)$, then $S$ is a strong symmetric sequencing iff $(y \mid p)=-1$ and $(y-1 \mid p)=1$.

(2) If $p \equiv 3(\bmod 4)$, then $S$ is a strong symmetric sequencing iff $(y \mid p)=-1$ and $(y-1 \mid p)=-1$.

Proof. This is clear from Theorems 3 and 4.

THEOREM 6. If $p \geqq 5$ is a prime, then $Z_{2 p}$ has a strong symmetric sequencing.

Proof. This follows immediately from Theorem 5 and facts about consecutive quadratic residues (e.g., see [7, p. 132]).

If $p=3$, then our process gives a symmetric sequencing of $Z_{6}$ but it fails to be strong.

We conclude by applying the methods of this paper to the construction of a Howell Design of type $H^{*}(14,16)$. Let $p=7$ and $2 y=x=12$. Then $p \equiv 3(\bmod 4)$ and $(y-1 \mid p)=(y \mid p)=-1$. Thus $S$ is a strong symmetric sequencing.

$$
\begin{aligned}
& S: \quad 0,12,10,8,1,3,5,7,9,11,13,6,4,2 \\
& P: \quad \underline{0}, \underline{12}, \underline{8}, \underline{2}, 3, \underline{6}, 11, \underline{4}, 13, \underline{10}, 9,1,5,7=p \\
& \text { C: } \quad \begin{array}{lllllll}
12 & 6 & 10 & 5 & 9 & 3 & 1
\end{array}
\end{aligned}
$$

Now the results of [1] tell us that

$$
E=\{\{12,8\},\{2,3\},\{6,11\},\{13,10\},\{9,1\},\{5,7\}\}
$$

is a "strong even starter" on $Z_{14}$ and that if $\alpha$ and $\beta$ are ideal elements added to $Z_{14}$,

$$
\alpha, 0--6,11-2,312,8-\beta, 413,109,1-5,7-
$$

is the first row of a starter-adder defined $H^{*}(14,16)$.

Added in proof. P. J. Schellenberg and S. A. Vanstone have shown, in a paper to appear in the Proc. Eleventh S.E. Conf. on 
Combinatorics, Graph Theory and Computing, that the design types mentioned in (B) and (C) exist.

\section{REFERENCES}

1. B. A. Anderson, Sequencings and starters, Pacific J. Math., 64 (1976), 17-24.

2. - Starters, digraphs and Howell Designs, Utilitas Math., 14 (1978), 219-248.

3. Howell designs of type $H(P-1, P+1)$, J. Combinatorial Theory Ser A, 24 (1978), 131-140.

4. - Hyperovals and Howell designs, Ars. Combinatorica, to appear.

5. B. A. Anderson and K. B. Gross, A partial starter construction, Proc. of the Ninth Southeastern Conf. on Comb., Graph Theory and Computing, (1978), 57-64.

6. B. A. Anderson, K. B. Gross and P. A. Leonard, Some Howell designs of prime side, Discrete Math., 28 (1979), 113-134.

7. G.E. Andrews, Number Theory, Saunders, 1971.

8. B. Gordon, Sequences in groups with distinct partial products, Pacific J. Math., 11 (1961), 1309-1313.

9. S. H. Y. Hung and N.S. Mendelsohn, On Howell designs, J. Combinatorial Theory Ser A, 16 (1974), 174-198.

10. R.C. Mullin and W. D. Wallis, The existence of Room squares, Aequationes Math., 13 (1975), 1-7.

Received April 17, 1979.

Arizona State University

Tempe, AZ 85281 


\section{PACIFIC JOURNAL OF MATHEMATICS}

\section{EDITORS}

DONALD BABBITT (Managing Editor)

University of California

Los Angeles, CA 90024

HUGo RossI

University of Utah

Salt Lake City, UT 84112

C. C. MOORE and ANDREW OGG

University of California

Berkeley, CA 94720
J. DUGUNDJI

Department of Mathematics

University of Southern California

Los Angeles, CA 90007

R. FinN and J. Milgram

Stanford University

Stanford, CA 94305

\section{ASSOCIATE EDITORS}
R. ARENS
E. F. BECKENBACH
B. H. NeumanN
F. WOLF
K. Yoshida

\section{SUPPORTING INSTITUTIONS}

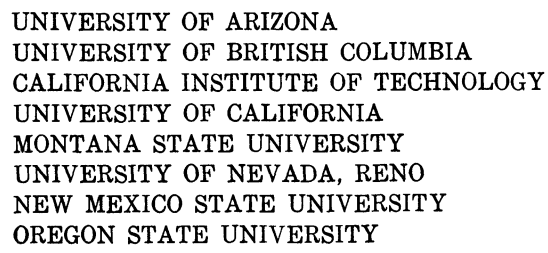

UNIVERSITY OF ARIZONA

UNIVERSITY OF BRITISH COLUMBIA CALIFORNIA INSTITUTE OF TECHNOLOGY

UNIVERSITY OF CALIFORNIA

MONTANA STATE UNIVERSITY

UNIVERSITY OF NEVADA, RENO

NEW MEXICO STATE UNIVERSITY

OREGON STATE UNIVERSITY

\author{
UNIVERSITY OF OREGON \\ UNIVERSITY OF SOUTHERN CALIFORNIA \\ STANFORD UNIVERSITY \\ UNIVERSITY OF HAWAII \\ UNIVERSITY OF TOKYO \\ UNIVERSITY OF UTAH \\ WASHINGTON STATE UNIVERSITY \\ UNIVERSITY OF WASHINGTON
}

The Supporting Institutions listed above contribute to the cost of publication of this Journal, but they are not owners or publishers and have no responsibility for its content or policies.

Mathematical papers intended for publication in the Pacific Journal of Mathematics should be in typed form or offset-reproduced, (not dittoed), double spaced with large margins. Please do not use built up fractions in the text of the manuscript. However, you may use them in the displayed equations. Underline Greek letters in red, German in green, and script in blue. The first paragraph or two must be capable of being used separately as a synopsis of the entire paper. Please propose a heading for the odd numbered pages of less than 35 characters. Manuscripts, in triplicate, may be sent to any one of the editors. Please classify according to the scheme of Math. Reviews, Index to Vol. 39. Supply name and address of author to whom proofs should be sent. All other communications should be addressed to the managing editor, or Elaine Barth, University of California, Los Angeles, California, 90024.

50 reprints to each author are provided free for each article, only if page charges have been substantially paid. Additional copies may be obtained at cost in multiples of 50 .

The Pacific Journal of Mathematics is issued monthly as of January 1966. Regular subscription rate: $\$ 102.00$ a year (6 Vols., 12 issues). Special rate: $\$ 51.00$ a year to individual members of supporting institutions.

Subscriptions, orders for numbers issued in the last three calendar years, and changes of address shoud be sent to Pacific Journal of Mathematics, P.O. Box 969, Carmel Valley, CA 93924, U.S.A Old back numbers obtainable from Kraus Periodicals Co., Route 100, Millwood, NY 10546.

\section{PUBLISHED BY PACIFIC JOURNAL OF MATHEMATICS, A NON-PROFIT CORPORATION}

Printed at Kokusai Bunken Insatsusha (International Academic Printing Co., Ltd.). 8-8, 3-chome, Takadanobaba, Shinjuku-ku, Tokyo 160, Japan. 


\section{Pacific Journal of Mathematics}

Vol. 92, No. $2 \quad$ February, 1981

Bruce Allem Anderson and Philip A. Leonard, Sequencings and Howell designs

Kevin T. Andrews, Representation of compact and weakly compact

operators on the space of Bochner integrable functions . . . . . . . . 257

James Glenn Brookshear, On the structure of hyper-real $z$-ultrafilters . . . . . 269

Frank John Forelli, Jr., A necessary condition on the extreme points of a class of holomorphic functions. II ...................... 277

Richard J. Friedlander, Basil Gordon and Peter Tannenbaum, Partitions of groups and complete mappings ......................... 283

Emden Robert Gansner, Matrix correspondences of plane partitions ......295

David Andrew Gay and William Yslas Vélez, The torsion group of a radical extension ..........................................

André (Piotrowsky) De Korvin and C. E. Roberts, Convergence theorems for some scalar valued integrals when the measure is Nemytskii ...... 329

Takaŝi Kusano and Manabu Naito, Oscillation criteria for general linear ordinary differential equations $\ldots \ldots \ldots \ldots \ldots \ldots \ldots \ldots \ldots \ldots \ldots \ldots \ldots \ldots \ldots \ldots$

Vo Thanh Liem, Homotopy dimension of some orbit spaces .......... 357

Mark Mahowald, $b o$-resolutions . . . . . . . . . . . . . . . . . . . 365

Jan van Mill and Marcel Lodewijk Johanna van de Vel, Subbases, convex

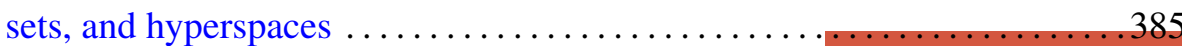

John F. Morrison, Approximations to real algebraic numbers by algebraic numbers of smaller degree $\ldots \ldots \ldots \ldots \ldots \ldots \ldots \ldots \ldots \ldots \ldots \ldots \ldots$

Caroline Series, An application of groupoid cohomology . . . . . . . . . . 415

Peter Frederick Stiller, Monodromy and invariants of elliptic surfaces . . . 433 Akihito Uchiyama, The factorization of $H^{p}$ on the space of homogeneous

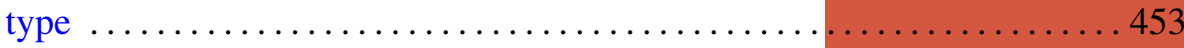

Warren James Wong, Maps on simple algebras preserving zero products.

II. Lie algebras of linear type 